\title{
How One University Harnessed Internal Knowledge and Expertise to Effectively Combat the COVID-19 Pandemic ${ }^{1}$
}

\author{
Antonio M. Calcado, Vicente Gracias, Brent D. Ruben, Jennifer St.Pierre and Brian L Strom \\ Rutgers University, USA \\ antonio.calcado@rutgers.edu \\ graciavh@rbhs.rutgers.edu \\ bruben@rutgers.edu \\ jstpierr@echo.rutgers.edu \\ bstrom@rbhs.rutgers.edu
}

\begin{abstract}
This case history provides a snapshot of the leadership and organizational context that supported a bold and collaborative decision-making process at Rutgers, The State University of New Jersey, highlighting the importance of a disciplined approach to information and communication that takes full advantage of internal resources and expertise. Rutgers was the first university in the United States to make and announce a decision to require COVID-19 vaccination of all students for fall 2021. The decision to protect the university community with a mandated vaccination effort was the cumulative result of more than a year's effort to sustain a campus environment that maintained some of the lowest COVID19 positivity rates in the country. From the outset, the announcement triggered extensive media coverage, an outpouring of reactions, and considerable debate that placed the university in the national spotlight. The university relied on its core values, internal subject-matter experts, information and communication resources, and collaborative leadership to guide, implement, and disseminate decisions. The successful health and safety outcomes that have resulted are no small feat when considering New Jersey and New York were the epicenter for the first east coast surge of the American COVID-19 Pandemic of 2020.
\end{abstract}

Keywords: COVID-19, Pandemic, Vaccination Requirement, Higher Education, Knowledge and Information Management, Collaborative Leadership, Crisis Management, Rapid Institutional Change, Population Health,

\section{Introduction}

The challenges associated with knowledge and information management can be significant in organizations of all kinds and in all sectors during a crisis. Obstacles to these processes are particularly notable within higher education (Rowley, 2000), where loosely-coupled systems, distributed leadership, decentralized decisionmaking, traditions of faculty autonomy, work-flow inefficiencies, and diverse role-based cultures magnify the usual organizational challenges (Birnbaum, 1988; Bueller, 2015; Cranfield and Taylor, 2008; Hendrickson, et al, 2013; Nuninger and Chatelet, 2016; Ruben, De Lisi and Gigliotti, 2021; Ruben, in press; Weick, 1976).

Although universities are understood to be in the knowledge business (Goddard, 1998) and should be well positioned to lead other sectors in the organization and use of knowledge for administrative purposes, this is not necessarily an area of distinction within many colleges and universities (Bhusry, Ranjan and Nagar, 2012).

Impediments to excellence in knowledge management arise from the absence of a culture of sharing, a lack of awareness of potential benefits, and a failure to integrate effective practices into work routines (Bhusry, Ranjan and Nagar, 2012). In such a context, the effective aggregation, curation, and communication of pertinent information-from both internal and external sources-present challenges at any point in time. These challenges are especially problematic during periods of disruption and crisis such as has occurred within higher education in response to the COVID-19 pandemic. (Ruben, 2020a, 2020b). However, when the power of such a community of academic, administrative, and professional experts is effectively harnessed and focused on addressing a problem, such as the pandemic, the knowledge available with the institution becomes apparent.

The result is a case history of how colleges and universities may address additional challenges confronting society if they are able to organize and leverage their resident knowledge.

\footnotetext{
${ }^{1}$ The authors are listed in alphabetical order and wish to gratefully acknowledge the contributions of Andrea Conklin Bueschel, Morit Blank, Jonathan Holloway, Melodee Lasky, Damian Onwunka, and Kim Tuby. 
Clearly, the impact of the pandemic has been pervasive and largely unprecedented for individuals and organizations worldwide. Like other organizations, higher-education institutions, and their faculty, staff, and students in the U.S. and internationally, have been confronted by life-threatening health and safety concerns.

Wide-ranging disruptions have often been quite extreme, even existential. These circumstances instigated critical moments calling for thoughtful and expeditious decision-making in a context in which leaders, students, and others in the institutions were compelled to pivot rapidly to remote technology to support all interactions.

This case history provides a snapshot of the leadership and organizational context that supported a bold and collaborative process at Rutgers, The State University of New Jersey (Rutgers) that harnessed internal expertise to overcome many of the usual impediments to effective, efficient, action-oriented, and informed decisionmaking. These efforts culminated in the decision to require vaccination of all students for fall 2021. Rutgers was the first university in the United States to make and announce this decision-a decision which was subsequently embraced by approximately 1,000 other colleges and universities and later by various public and private organizations (Thomason and O'Leary, September, 2020). The background, setting, and processes through which this occurred are profiled in this article, along with a discussion of insights that emerged and implications for effectively utilizing internal knowledge resources and collaborative leadership in other crisis settings within higher education and perhaps in a broader range of contexts.

\section{Research Methodology}

This article utilizes a narrative approach, drawing on qualitative and quantitative data to provide a case history of events associated with the efforts of one large U.S. research university to address a life-threatening crisis confronting the community. The project analyzes public documents, media accounts, and interviews with selected university leaders and key decision makers to describe the manner in which internal sources of expertise and knowledge were identified and integrated to facilitate rapid, coordinated, value-based decisionmaking and execution. The study considers ways in which what Davenport, Delong and Beers (1998) and Rowley (2000, p. 327) describe as "explicit, documented knowledge, and tacit, subjective knowledge" were shared and collaboratively utilized to become vital organizational assets at a critical moment for the institution.

\section{The National and State Context}

In late January 2020, many in the U.S. became aware of the novel coronavirus first detected in China when news arrived that a case had been confirmed in Washington state (New York Times, Jan 21, 2020). Within 10 days Wuhan, China and the surrounding communities were on lockdown, and the World Health Organization (WHO) declared a public health emergency. As the virus spread, organizational leaders across the country took note of guidance as it flowed from the Centers of Disease Control and Infection (CDC) to state departments of health and then to local health departments.

As one of the initial sites for extensive spread of the virus, New Jersey (NJ) along with New York were among the first to battle the pandemic. New Jersey is the most densely populated state in the U.S. with one of the most diverse and global populations. These demographics coupled with the state's locale and centrality relative to significant travel corridors (New York, Philadelphia, District of Colombia, and Boston) and around major international airports contributed to its susceptibility to an airborne transmissible disease arriving from overseas.

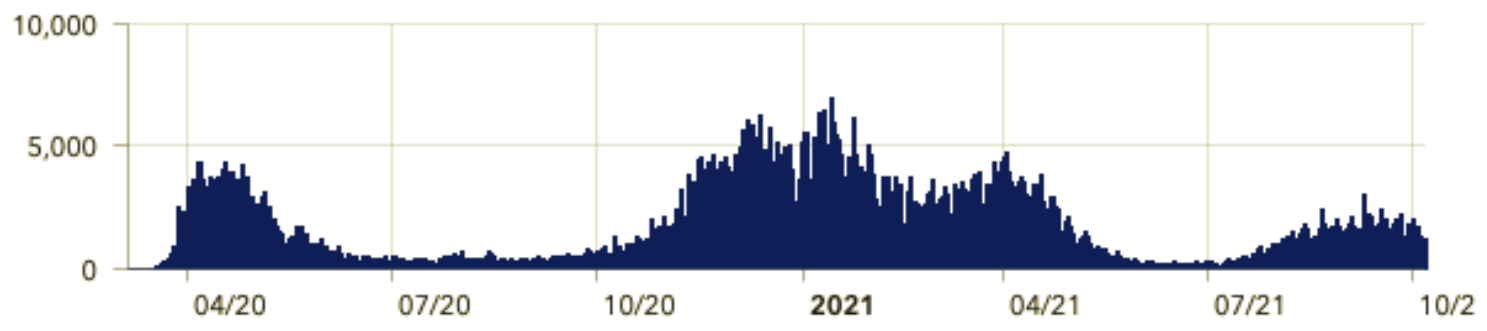

Figure 1: NJ COVID-19 Dashboard Confirmed COVID-19 Cases Over Time

(Source: https://www.nj.gov/health/cd/topics/covid2019 dashboard.shtml) 
New Jersey Governor Phil Murphy issued executive order 104 on March 16, 2020 limiting gatherings to 50 individuals, closing non-essential businesses and schools, and ending in-person instruction at higher-education institutions within the state beginning March 18 . Although positivity rates within the community were unknown throughout much of that spring due to limited availability of testing, the virus's prevalence was evident within NJ's overwhelmed hospitals and mounting mortality.

\section{The University Context}

The COVID-19 pandemic created extraordinary crisis conditions for organizations in various sectors, including higher education (Chronicle of Higher Education, 2020b). In a matter of days, colleges and universities had to confront organizational challenges related to instructional delivery, campus openings and closings (temporary and permanent), long-term financial stability (Chronicle of Higher Education, 2020a; Associated Press, 2020), employment (Chronicle of Higher Education, 2020b), campus governance, faculty engagement in decisionmaking, confidence in administrators (Flaherty, 2020; Murphy, 2020; Paquette, 2020), and many other issues (Fernandes, 2020; Furstenberg, 2020; Nadworny, 2020; Ruben, 2020b; Vedder, 2020; Zahneis, 2020; Zwickel, 2020).

The crisis for higher education is defined by four conditions that have been extremely difficult to resolve:

1. Social distancing in an industry where social interaction and physical presence are central to the work done, whether in the classroom, dormitories, and fraternities or sororities, or in the laboratories, libraries, clinics, and field sites where students and faculty conduct their research.

2. Fiscal emergencies in a sector that has confronted financial challenges for some time, especially-but not exclusively- at schools that receive state funding, and at small private institutions that were struggling financially. The unpredictability of demand/tuition revenue as well as the impact from auxiliary services; such as housing, athletics, facility rentals, campus stores, and restaurants, etc., coupled with increased financial need among students, also contributed to the strain on the university. Loss of international students, most of whom pay full tuition, could exacerbate financial challenges.

3. Increasing demand for health care services delivered in hazardous conditions for those schools with medical schools, other health professional schools, or hospitals, while simultaneously losing revenue from delayed elective surgeries contributed mounting strain on already pressured leadership to produce more, with less (Lawrence, 2020).

4. The lack of a human or technological infrastructure to pivot to an all-remote environment.

Rutgers is a large and complex teaching-research institution with campuses and satellite facilities located throughout the state of NJ. Collective senior-level governance of the institution is provided by a Board of Governors, the university president, the president's cabinet which is composed of academic and administrative leaders, and four chancellors that oversee the institution's three regional and one united health sciences campuses. The State, and the university specifically, are highly unionized.

The university is home to more than 28,000 faculty and staff and 66,000+ students. Its largest campus, both in size and population, is Rutgers-New Brunswick. Rutgers-Newark and Rutgers-Camden also host sizeable academic and research programs, and Rutgers Biomedical and Health Sciences (RBHS) - which includes health care providers, instructors, researchers, and medical residents and fellows in addition to undergraduate students, graduate students, and academic faculty - has a major presence on each of the campuses and at numerous locations throughout the state.

While the functions described above are common to many if not most large universities and systems, the combination of Rutgers' size, organizational complexity, geographic dispersion, and urban campus settings were important considerations for leaders in planning and implementing COVID-19 policy. Administrators at all levels were involved in the process. Along with the university president, members of the university cabinet played important leadership roles in this regard, representing these critical functions: academic affairs, general counsel, human resources, IT, and communications. Each had a vital role to play in their respective area of expertise. The Office of Information Technology focused their efforts on preparing technology and providing technological support for faculty. Human Resources efforts centered on workforce policy, support, and labor relationships. Communications coordinated information dissemination from and to administrators and the community. Chancellors, their provosts, members of their leadership teams, and other unit's functional leaders provided 
important input and supported communication efforts with their communities throughout the pandemic. Ongoing clear communication across the university was necessary to maintain coordination and overcome fears as the pandemic intensified and anxiety became an enemy of providing effective, timely, equitable, and safe education and patient care. All of these efforts depended on the deployment and integration of all Rutgers statewide enterprises through one central coordinated approach, reacting to the pandemic's rapidly changing landscape across the most densely populated state in America.

\subsection{A Leader in Health}

A key asset to the university during this period was the expertise and leadership present within its own academic medical centers. Dedicated to advancing medical research, education, outreach, and clinical practice, RBHS employs renowned experts throughout the varied fields of health and wellness and is led by physician and epidemiologist Brian L. Strom, a long-term member of the National Academy of Medicine, with special expertise in the effects of drugs and vaccines. More than 1,300 health care professionals including dentists, nurses, psychologists, pharmacists, and other allied health providers comprise RBHS's clinical care division, Rutgers Health. Each year Rutgers Health delivers 2.8 million patient visits and performs 470 clinical trials. Additionally, Rutgers University and RWJBarnabas Health, NJ's largest and most comprehensive health care delivery system, recently partnered to create one of the largest academic health systems in the U.S., and the largest in the state of NJ. The collaboration between the two entities supports the training of more than 1,500 medical residents and interns and includes substantial investments in research.

RBHS's Chancellor and Senior Vice Chancellor of Clinical Affairs also guide universitywide health services as Executive Vice President of Health Affairs and Vice President of Health Affairs, respectively. Along with a former NJ Health Commissioner as the Executive Director of Health Systems and Population Health Integration and the Assistant Vice President of Student Health, Rutgers Health Affairs organized the institution's historically siloed, campus-specific student and occupational health offices into a coordinated and agile team that could quickly advise university leadership and guide the Rutgers community as a whole.

This valuable expertise also supported the university's clinical partners, as Rutgers served a key role in coordinating practices among its multiple health system partners and the university provided subject matter experts to the state government, lending critical expertise during a period when best practices were not yet known or confirmed.

\section{Decision-making Complexity and Challenges}

Throughout the pandemic, health care, academic, and administrative leaders were confronted by an unending array of decisions to be made, each requiring analysis, mapping to and weighing against potential consequences, implementation, and follow up. Beyond fundamental issues related to the initial health and safety of the university community, further decisions concerning renewal, repopulating, and reenergizing campuses needed to be addressed often while preparing for sometimes unpredictable health and safety concerns that emerged as the pandemic evolved. Transcending these decisions were efforts to maintain core values, promote resilience, and bolster a sense of community while direct interpersonal and organizational contact was restricted.

\subsection{Coordinating the Rutgers Response}

The Office of Emergency Management, led by the university's Emergency Management Coordinator, was central to coordinating the university's response and the formation of the governance structure by which the university would make and execute all decisions.

On February 10, 2020 an initial Emergency Operations Team meeting was organized to establish regular briefings and on February 28 the university activated its Emergency Operations Center (EOC) to deal with the emerging threat and call all-hands-on-deck. The EOC assembled 14 Teams with more than 200 members. Team leads were senior-level individuals at the university, and members were subject-matter experts. Tasks were identified for each team, a governance structure was put in place, and a cadence of meetings was established.

The Executive Team (ET) was led by the president and included the four chancellors and the Executive Vice President and Chief Operating Officer who was the chair of both the EOC and the ET. 
The activation of the EOC further elevated planning across the university and expanded resources dedicated to gathering and sharing pertinent information within the decision-making teams and developing and disseminating a unified response to the community. Under the guidance of the EOC, multiple teams and committees were conceived, launched, evolved, and dismantled as necessity ebbed and flowed. During this time Rutgers Health Affairs leaders continued to offer critical guidance to the university through the EOC, as well as leading several EOC sub-committees focused on addressing the health concerns of the university, and more largely for the state, as it navigated the height of the crisis. During the early stages of the pandemic the EOC and the ET met daily to review countless questions and make decisions necessary to keep university functions operating. RBHS clinical deans and institute directors met nightly to respond to the crises and shortages of the day, and RBHS coordinated very closely with its hospital partners and the New Jersey Department of Health. EOC Team Leads met regularly to address all outstanding issues.

Collectively this group was charged with maintaining clear alignment of clinical and operational guidance across all campuses. Often data or governmental guidance was not available or delayed, and decisions had to be weighed and distributed to offer the best chance at maintaining a cohesive defense against the growing number of sick and dying patients. The EOC monitored CDC and world data to make informed predictions in order to withstand the pandemic and deliver against all of Rutgers' missions in as safe an environment as possible.

In the early stages of what would eventually become the pandemic, a small Health Affairs Response Team (HART) consisting of representatives from clinical affairs, student health, occupational health, population health, and communications monitored developments and guided early university response. Initial guidance was primarily focused on the university's global academic programs and advising the internal population to adhere to traditional virus-prevention tactics. HART grew alongside the pandemic, integrating and empowering representatives from operations, student affairs, state information systems, and others as needed. As detection of the novel coronavirus, and its subsequent "community spread" was announced in the United States and devastating illness and loss of life erupted in Italy, preparations and contingencies were developed within the university to provide resources and stability while external guidance and support faltered.

Within just 15 days the assembled teams worked together to cancel all study abroad programs and all university travel and depopulate the campuses by encouraging international students and visiting faculty to return home immediately, moving all students who were able from their residence halls to their homes, and introducing telecommuting and COVID-19 leave policies for employees. On March 14 the university was first alerted to a positive case of COVID-19 on campus, and on March 17 the university cancelled in-person commencement ceremonies, having readied itself for the storm to come. Just a few weeks later, Rutgers expedited virtual graduations of several cohorts of clinical students to help provide lifesaving clinical care in the state's overwhelmed hospitals.

In late spring 2020, the university continued mitigation strategies, cancelled Summer Session, and continued contingency planning for fall 2020. The EOC continued to meet on a weekly basis, with a larger working group of about 35 members joining on a bi-weekly cadence. During this time, the team focused on aligning with New Jersey Governor Murphy's Executive Orders and the State Office of the Secretary of Higher Education (OSHE) requirements and articulating the guidance in a comprehensive "Return to Rutgers" document that would inform operations for every university location and program.

In the middle of the year a university leadership transition took place with Dr. Jonathan S. Holloway, a U.S. historian and former provost of Northwestern, succeeding Dr. Robert L. Barchi, a neuroscientist who had served in the position since 2012. The announcement of the appointment of President Holloway in January 2020 contributed to a smooth transition by enabling briefings and consultation throughout the spring semester.

On the sixth day of his tenure, President Holloway announced that Rutgers would plan for a primarily remote Fall 2020 with a limited number of in-person classes. This decision was a departure from the direction that was taken by many peer institutions, but one that university leadership felt necessary due to Rutgers size, complexity, and location within urban and population-dense environments.

Mitigation through testing and tracing expanded and continued through the fall and was extended into the spring 2021 semester with a slightly increased on-campus student population. 
As the weeks and months of the crisis advanced, it became increasingly apparent that, rather than simply returning to "business as usual," a "new normal" would need to be defined, along with new ways to guide the review and adjustments, and in some cases more fundamental reprioritization of mission-critical functions, programs, services, work roles, and many other operational concerns (Ruben, 2020a). Indeed, as the pandemic progressed into a new endemic stage, it was clear that all of these issues would need to be addressed-and that that need would likely continue for some time into the future.

Adding immeasurably to the intensity and significance of leadership decision-making has been the pervasive, continuing, and evolving threat to campus safety and the health and safety of students, faculty, and staff. Before the pandemic was recognized as a national emergency, many universities with health care enterprises already felt the challenge of guaranteeing a safe environment for patients, students, employees, and the university community at large. At Rutgers, reorganization of core central health care clinical command was judged to be critical to produce fluid and rapid decision making and guidance for care coordination across sites.

To facilitate communication, often overlapping committees and subcommittees comprised of deans, directors, and other senior leadership from student health, behavioral health, and ambulatory practices among others, met frequently (at times semi-weekly) and also included central administrative representatives from environmental health and safety, systems engineering, communications, general counsel, and human resources as needed. Leads for each sub-committee advised appropriate action, centralized resource requests, and provided timely reports as the pandemic evolved. The Vice President for Health Affairs served as the chair of the clinical EOC, and coordinated all activities and information regarding global pandemic observation, local and national trends, clinical operations and intercampus readiness, and coordination with the NJ Department of Health, driving all information into the EOC central command.

This collaborative structure and supporting communication processes were established to collect, manage, and disseminate information, and to allow for organizing and channeling questions and queries on each major and minor decision and milestone to decision-makers. This approach was intended to promote clarity, enhance the sense of ownership, and encourage adherence to defined operating procedures across the university.

\section{Vaccine Availability}

Hope of relief from the crisis began to build in late summer and early fall of 2020 as three vaccine candidates entered phase three clinical trials. In mid-December the two MRNA vaccines received FDA EUA approval. Due to limited supply, vaccination eligibility was announced in stages to prioritize availability for those most at risk. The first vaccination in NJ was administered to Maritza Beniquez, a nurse at University Hospital in Newark on December 16, 2020.

Expanded eligibility for all adults in NJ was granted on April 19, 2021. Initial and then confirmatory subsequent data indicated that the vaccines are extremely effective at preventing serious illness from COVID-19, and cases throughout the state dropped significantly as vaccination increased. 


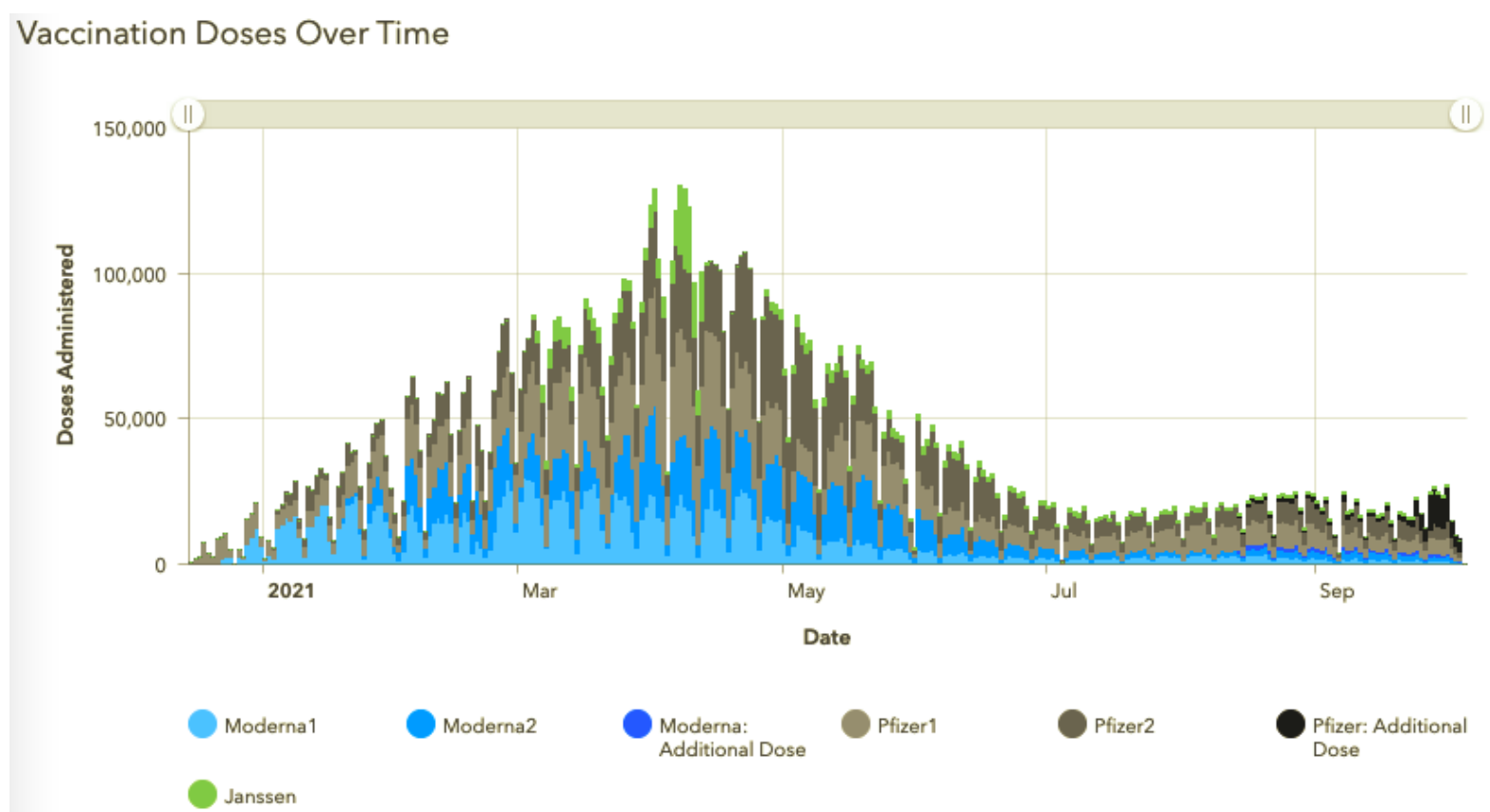

Figure 2: NJ COVID-19 Dashboard COVID-19 Vaccine Doses Administered Over Time.

Source: (NJ COVID Dashboard, October 5, 2021)

\section{Vaccination-related Decision Making}

As vaccination was initiated across the country, Rutgers leadership began evaluating the role vaccines could play in a safe return to campus. As time passed, and more data became available, skepticism related to the efficacy and safety of the vaccines shifted to tempered optimism. The remaining hurdles were availability and public perception.

In January 2021 the university cancelled Summer Session 2021 and started to have critical conversations about what all Fall 2021 would look like. Over the next eight weeks university leaders consulted with health agencies as well as their own health experts and internal departments to determine the best course forward for the wellbeing of the $28,000+$ employees and the $66,000+$ students at the university.

Despite emerging variants, data suggested that the vaccines remained effective at preventing serious illness from COVID-19, and an internal survey distributed to all university community members indicated a strong willingness for vaccination.

University leaders weighed the value of various levels of vaccination within the community. Within the university's own testing program positivity rates among the student population $(1.29 \%)$ were double that of employees $(0.63 \%)$. Though risk of serious illness seemed less common within the student age group, the university needed to weigh the safety of all of its constituencies - including the members of the communities in which each of the university's campuses reside: New Brunswick/Piscataway, Newark, and Camden (Rutgers Testing Program Dashboard, Sept 11, 2021).

University leaders scanned the higher-education landscape, focusing particularly on peer institutions and also on the broader national community for a model to help guide them, and found that none had yet emerged.

With decision day for accepted students fast approaching and Fall 2021 course registration set to open in the end of March, the university was looking to make a determination about the fall semester. At the beginning of March, President Biden announced that vaccine supply would be available for everyone aged 16 and up by July.

The university's senior leadership team reconvened and reviewed all relevant information. The vaccines were effective and safe, vaccines would be available to all university community members who wanted them, and community spread of COVID-19 remained a threat to all who were unvaccinated. 


\section{The Announcement}

During the first two weeks in March, university administrators finalized plans for the vaccination requirement. The announcement of the mandate needed to be clear and communicated early enough to ensure that students were informed with ample time to weigh their options.

On March 25 2021, when Rutgers announced the decision to require students to be vaccinated in order to enroll in the Fall semester (Rutgers Office of the President, Mar 25, 2021), it became the first institution to do so (Durkee, Mar. 25, 2021). That morning the university had alerted the governor's office and OSHE of the forthcoming announcement. The mandate was announced initially in a message to the university community from President Holloway, Executive Vice President for Academic Affairs Prabhas V. Moghe, and Executive Vice President and Chief Operating Officer Antonio M. Calcado. The announcement stated that the policy would apply to all students except in cases where medical or religious reasons would be permitted. Vaccinations would not be required for students enrolled in purely online degree programs and individuals participating in online-only continuing education programs.

Rutgers President Jonathan Holloway prefaced the announcement of the policy in this way: "We are committed to the health and safety for all members of our community and adding COVID-19 vaccination to our student immunization requirements will help provide a safer and more robust college experience for our students" (Rutgers Today, Mar 25, 2021).

Commenting further, Antonio Calcado, executive vice president and chief operating officer explained that "Since the start of the pandemic, we have said that the safety of the Rutgers community is a shared responsibility. An effective vaccination program is a continuation of Rutgers' commitment to health and safety for all members of our community of more than 71,000 students, the cities we are in and the communities we serve throughout New Jersey."

The official press statement also included a statement from Brian Strom, chancellor of Rutgers Biomedical and Health Sciences and executive vice president for health affairs at the university. "The COVID-19 vaccines have proven to be safe and effective in preventing serious illness, hospitalization and death. Vaccination is key to stopping the current pandemic and to the return of campus instruction and activities closer to what we were accustomed to before the pandemic drastically changed life at Rutgers" (Rutgers Today, Mar 25, 2021). The announcement also noted that faculty and staff were strongly urged to receive the vaccine.

\subsection{A Bold Action}

As explained by President Holloway, there had been no intention to be the first institution to make such an announcement. There was, however, a conscious effort to arrive at and communicate a decision as early as possible so that students or parents who felt they could not comfortably comply with this guidance would have time to pursue other options for the fall (Holloway, Sept 3, 2021).

The announcement triggered a pattern that would eventually lead to adoption of the same course of action by approximately 1,000 institutions in subsequent days and weeks, representing an impressive leadership moment for Rutgers, and for higher education in general (Redden, Sept 21, 2021). The graph presented in Figure 3 shows the rate at which universities/colleges have made their announcements of required vaccines.

In an uncharacteristic endorsement, and what turned out to be a very accurate prediction of future events, Anthony S. Fauci, director of the National Institute of Allergy and Infectious Diseases and President Biden's chief medical adviser offered the following observations as a forecast of future developments within the higher education community and beyond.

You would wish that people would see why it's so important to get vaccinated... I know that people must like to have their individual freedom and not be told to do something, but I think we're in such a serious situation now that I think in certain circumstances, mandates should be done. When that occurs, which I hope will be really quite soon, I think you're going to see that local institutions, local enterprises are going to feel empowered - and ... they're going to be saying that if you want to go to this university or you want to go to this college, you've got to be vaccinated. (Bellows, Aug 10, 2021) 
In the days that followed, media engagements were selectively accepted for university, local, statewide, and national outlets. Supporting messages cascaded from leadership across the campuses, and content was developed and disseminated across university media properties to help students understand the requirements and the directions for uploading their documentation.

"(Students) deserve to have the experience that they have been looking forward to, and we think this is a small price to pay to do it," said Antonio Calcado in an interview with CNN. "We already require and mandate a number of different vaccines so we have a policy in place." (Golodryga, Apr 23, 2021)

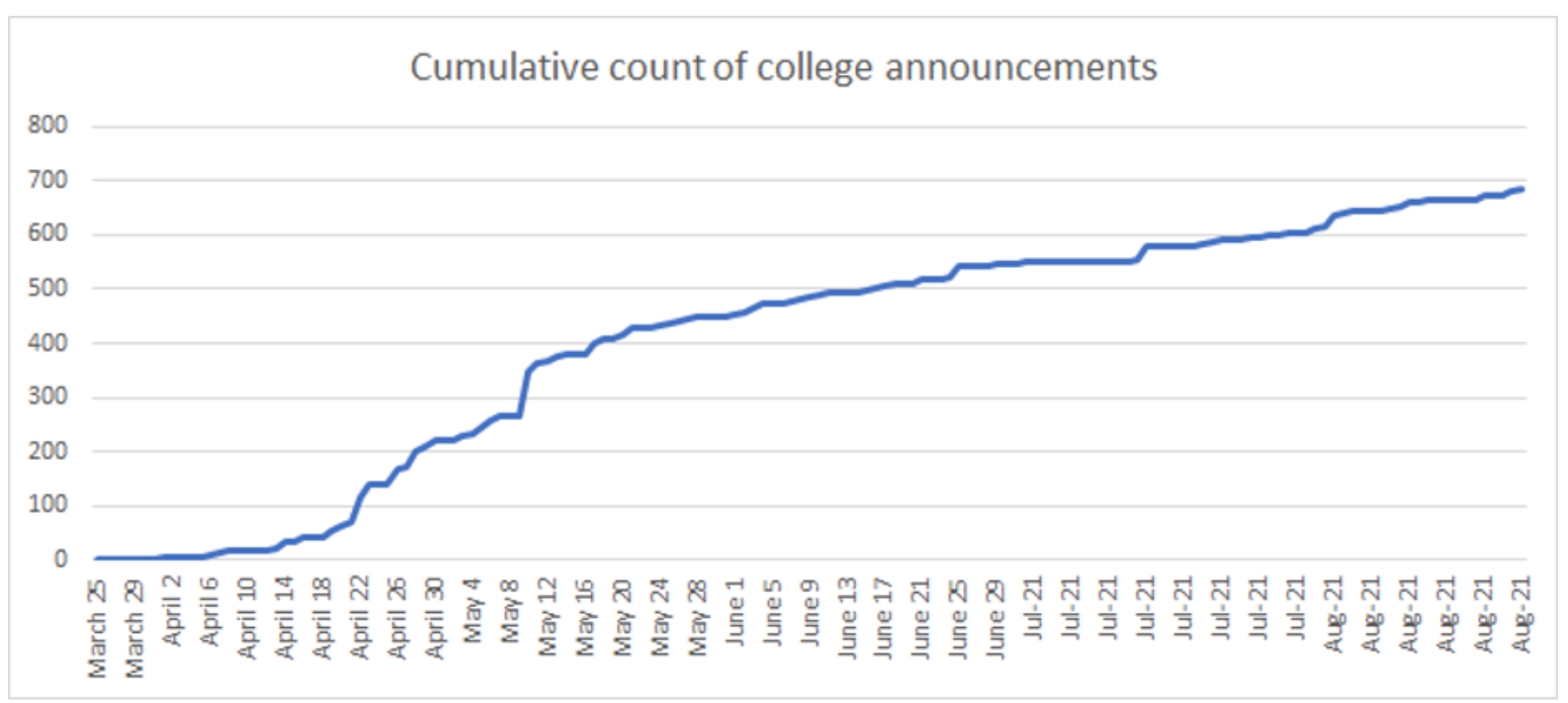

Figure 3: University Vaccine Mandate Announcements Over Time

(Source: Thomason and O'Leary, Aug 21, 2021, The Chronicle of Higher Education)

\subsection{Follow-up}

When the decision of the student vaccination mandate became known, Rutgers administrators quickly began working on implementing the policy. Frameworks already existed for both student and employee inoculation policies - but only for limited segments of those populations. Together, employees from Health Affairs, Occupational Health, Student Health, Student Affairs, General Counsel, Human Resources, Institutional Planning and Operations, Information Technology, and Communications worked expeditiously to update the existing policies, build systems, create processes, and define compliance expectations necessary in order to enact the requirement.

Traditionally, immunization requirements for all incoming undergraduate students include Measles, Mumps, Rubella, Meningitis, Tuberculosis, and Hepatitis b. Students who participate in clinical activities are also required to have received additional inoculations for Varicella, Tetanus-diphtheria-pertussis, and annually Influenza. University employees who are identified as "covered individuals" (typically those who provide clinical care or are physically located within spaces that do so) are required to attest to inoculation against Annual Influenza. The updates to the two relevant policies expanded their application to include returning undergraduate students and all graduate students.

An immediate need was a comprehensive centralized information system that harnessed data from student record systems as well as the Rutgers COVID-19 testing and COVID-19 vaccination systems and cross communicated between them. The parameters of the system were established by subject matter experts from health affairs, student health, occupational health, clinical affairs, information technology, communications, human resources, admissions, general counsel, and more. Built progressively by a highly skilled internal programmer as the pandemic evolved, first with testing and then with vaccine administration - the "Return to Rutgers" system was further expanded to integrate vaccine documentation upload and review. The resulting system enabled users to schedule vaccination and/or testing appointments, upload their relevant documentation, and view status updates. Most importantly it allowed university administrators to monitor 
activity, report on compliance, and communicate with targeted segments of the population based on level of compliance.

Verification committees consisting of trained health professionals within the university were quickly assembled and expanded to address the increased volume of student records to be reviewed and approved. Committee leaders also were challenged to define expectations for the term "fully vaccinated" for a population that included international students and personnel with differing and at times limited, access to vaccines.

Each of the COVID-19 vaccine mandate policies allowed exemptions to be requested by students for medical or religious reasons. Though these same exemption opportunities were available within the existing policies, they were rarely requested. Additional internal committees were convened to address the need to process an anticipated significant increase in exemption requests. The exemption committees were charged with reviewing and expanding upon the existing criteria for exemptions as necessary. It was critical that both the verification and exemption committee groups ensured consistent application of their criteria throughout the university and that they worked quickly. The process for both groups was often slowed by necessary correspondence between the reviewers (which may or may not be the same individual) and the submitter as technical problems, user error, or additional information requests were addressed. As the summer passed, and the deadline for record upload loomed, both groups of committees also faced the burden of processing escalating submissions.

Clear, consistent information and communication were required to convey the intention of the vaccine requirements, gain support from the community, provide necessary details for all university groups covered by the policies, and identify and clarify misunderstandings and concerns. A representative from university communications was embedded within the health affairs leadership group to provide proactive guidance and streamline the development of key messages and their delivery methods. Messages were strategically targeted to address evolving concerns including campus health and safety, vaccine safety and effectiveness, vaccine availability, vaccine hesitancy, vaccine documentation requirements, and more. Primary audiences included: incoming students, returning students, international students, and university employees. Multiple communication channels were employed as appropriate to each message and the target audience.

As attention shifted from deliberation to implementation, a primary concern became informing key audiences of the parameters of the policies and encouraging them to take action. This required clear definitions of compliance (what documentation was required, of whom, by when, and how it should be submitted) and what the consequences of non-compliance would be. Information related to requirements was conveyed using university media including websites, learning management tools, social media accounts, campus digital signage, and others. Tailored messages were delivered regularly to students segmented by their role (returning student, incoming student, international student, etc.) and status (non-compliant, semi-compliant, pending review, fully compliant).

Communication related to vaccine hesitancy was also a priority. The Rutgers Vaccination Portal was designed ahead of the vaccine mandates in early spring 2021 as a repository for the records of the health care professional and other employees who were among the first in the nation to become vaccinated. Though eager to receive the vaccinations, some of the employees were reluctant to share their health records with the university due to privacy and security concerns. These issues were addressed by providing general information regarding the security of the information systems that held the data as well as the governance that dictated who would have access to detailed information and how that information would be aggregated into reports. The more challenging issue to address was the reluctance to become vaccinated.

Messages were created relative to key vaccine hesitancy issues, including: 1) the efficacy of the available vaccines; 2 ) the safety of the available vaccines; 3 ) the validity of the emergency use authorization (EUA) process; and 4) the toll of COVID-19 on individuals and within the community. These messages were primarily delivered by the university's medical experts and trusted student and university leaders through traditional channels and new platforms that were developed such as virtual townhalls, live web-based health briefings, and podcasts. Campus news platforms and other media were also used to disseminate these messages to external audiences. 


\subsection{A Bold Decision with Impressive Results}

From the outset the announcement triggered extensive media coverage, an outpouring of reactions, and considerable debate that placed the university in the national spotlight. Rarely has there been a circumstance where a higher education leadership decision has garnered as much national attention, touched on as many concerns, been as widely scrutinized, or acted on with such rapidity and consistency across the higher education community.

The outcomes from this process have been impressive. For the fall 2021 semester, the university deregistered only 60 students out of a total of 64,636, enabling Rutgers' campuses to return to full capacity, with every able employee and student returning to work and learning at pre-pandemic levels under the guidance of carefully detailed operating instructions (Update to the Guide, Aug 27, 2021). Rutgers rates of disease have been consistently far below that of the surrounding region [see Figure 4], which has been better than much of the rest of the country after passing through its initial surge.

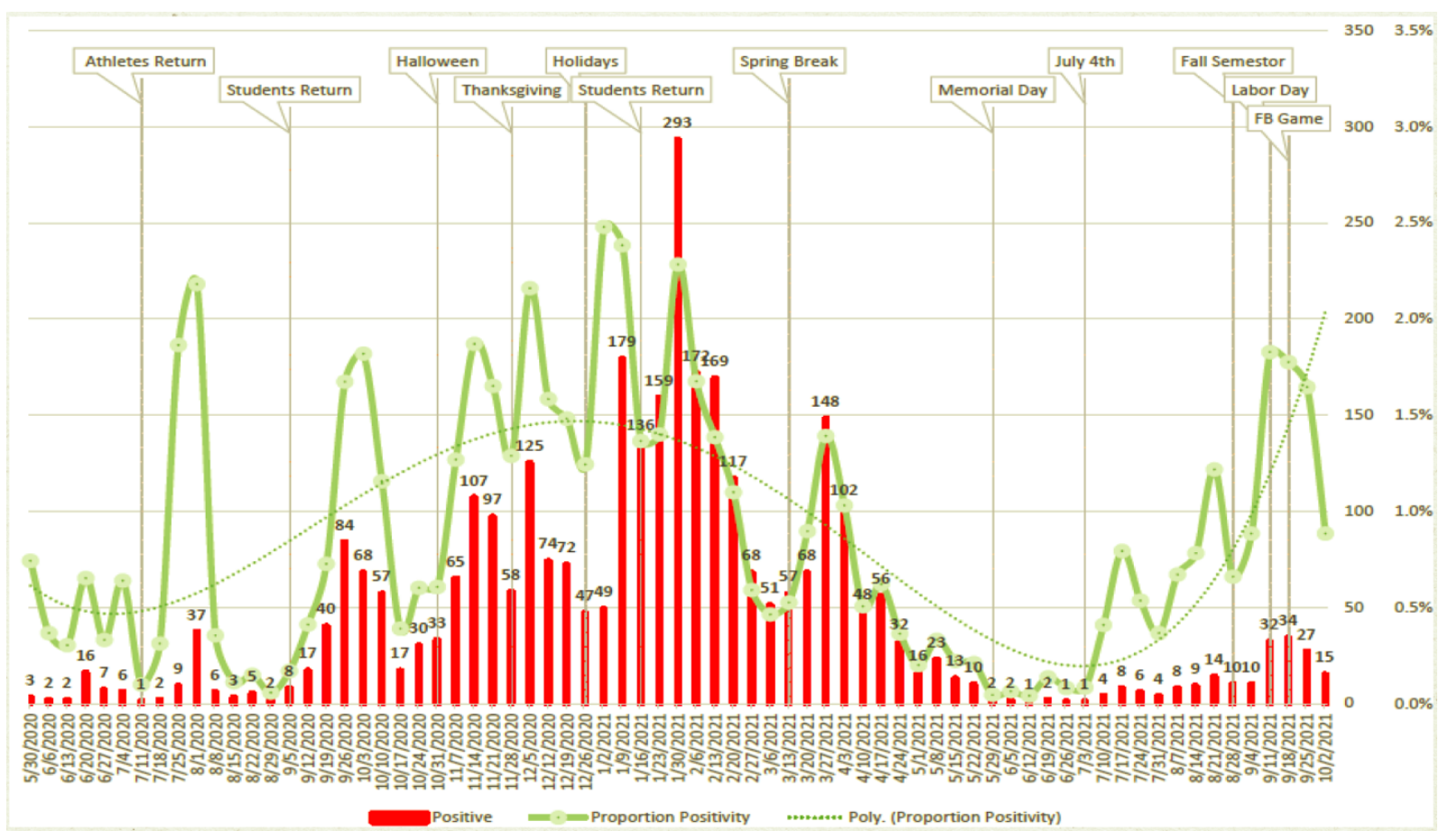

Figure 4: Rutgers University Testing Program Case Positivity Rate Over Time

Unquestionably, the decision to require vaccination among returning students-and to assume a leadership role among higher education institutions in doing so-was a bold action. It is not customary for colleges and universities to lead the way in decisions that have such broad implications, nor to arrive at such a decision in what may have seemed to be a short amount of time. It was quite clear from earlier experiences globally, however, that hesitation would result in misinformation, confusion, fear, and degraded community cohesion, and ultimately serious illness and the loss of life.

From the beginning, Rutgers was on the front lines, using the full power of its science, innovation, and determination with the aim of creating an oasis of health within a very threatening environment. The university responded to the global emergency in ways big and small, including among other things: by sharing their expertise and factual and steady analysis to an anxious and uneasy world; by creating a better way to test for COVID-19 and sharing this discovery with the world; by working with hospital and health system partners to care for the sick and then researching how the disease impacted those providing care; by graduating medical, pharmacy, and nursing students early so that they could join the front lines sooner; by partnering with the State of NJ (Edelstein, June 10, 2020) to mitigate spread of the disease; and by conducting studies of vaccines (Hosseini, Sept 1, 2020).

Throughout the pandemic, university leaders were required to use incomplete information to make the best decision possible in a time of unprecedented uncertainty. The university's data gathering, deliberations, action 
planning, and implementation efforts moved with remarkable speed to support decision-making that was data informed, collaborative, and carefully reviewed. The process required consideration of an extraordinarily broad array of perspectives including medical, legal, ethical, political, campus safety, facilities, economic, risk management, political, students and parents, faculty and staff, unions, and other stakeholder groups.

Each decision was guided by the university's mission to its support students, employees, patients, and surrounding communities, and to cultivate an environment of exploration, healing, innovation, and discovery. Successful adherence to these values was made possible by the tireless work of the fourteen teams: Human Resources, Information Technology, Academic Affairs, Facilities, Finance, Communications, Health Affairs and Clinical Affairs, Research, Student Affairs, Student Health, Emergency Management, President's Office, Secretary's Office, and Office of General Counsel.

It is too soon to tell what the legacy of the pandemic and its effect on the university community will be. Outside of the required rapid reevaluation of how learning and work is performed, it is hoped that society's renewed appreciation for science, wellness, and the health professions will usher in a renaissance of life-changing discoveries, ground-breaking and integrated treatments, and a commitment to ensuring that everyone receives the care they deserve.

\subsection{Future Uncertainties as the Pandemic and Planning Enters a New Phase: A Work in Progress}

At this point this disease is more likely to evolve to being endemic, than for the pandemic to end. It is also worth noting in this connection that the authors have struggled with determining where this case history should begin and end. We are now entering the third academic year of disruption, and each day new developments further blur this issue. An early thought was to focus the case on the decision, announcement, and follow-up communication related to the vaccine requirement. However, as we worked forward, it became apparent that the broader environmental and organization context-what went before-was a necessary part of the story required to understand the success of the organizational decision-making, its widespread acceptance, and the broader influence of the vaccination decision within a unified university community and beyond.

In spite of these complications, we believe it is important to chronicle the case as we have to this point in time. First, we believe there can be considerable value in analyzing the leadership effort-even though it is a "work in progress" - to better understand the encouraging outcomes that have resulted thus far. Second, we believe there are a number of interesting and important insights and generalizations that can be identified that may be helpful for leaders at other institutions in dealing with COVID-19-related challenges and other complex institutional challenges going forward. Third, as noted, it is not possible to determine now when or if the situation being described will reach a natural end point, or at least a plateau; when and if that happens, we are concerned that so much time is likely to have passed that the key events described herein will be far more challenging to extract, capture, and convey than they are now, and many possibly valuable lessons will not have been shared with others who could use them now.

\section{9. “Lessons Learned"}

In this section, the article offers several observations related to leadership, management, and organizational principles and practices based on the outcomes to this point in time after two successful academic years during the COVID-19 pandemic. While a narrative such as this suggests a number of useful practices and procedures addressing a pandemic-scale crisis within a large campus community, a number of other more general insights can be drawn through reflection on this case. These generic observations have potential applicability across contexts and circumstances where challenges related to leadership, information, and organizational processes are involved. The following sections identify and briefly address a number of these.

\subsection{Values-Guided, Collaborative Leadership}

A first critical insight gained from the case analysis relates to the critical role of core values and the way they have been used by leaders to create and guide the COVID-19 strategy from beginning to end. As articulated by President Holloway and his colleagues on the leadership team, these values guided all phases of university strategy planning and execution: 1) the health and safety of students, faculty, and staff; 2) acting in accordance with the guidance provided by science and the medical community; and 3) timely and flexible decision-making in order to provide as much opportunity for students, faculty, and staff to plan and prepare (Holloway, Sept 3, 2021). 
While many other considerations and concerns were at play, having a clear and shared set of guiding principles in terms of which to evaluate suggestions, weigh alternative courses of action, and formulate and enact plans in a consistent manner was a defining element of the leadership approach, one that served the team and the community at large very well.

\subsection{Leveraging Internal Experts and Expertise}

From the outset, an important aspect of the planning and implementation effort was the use of internal subjectmatter experts and expertise. Many colleges and universities have an amazing wealth of in-house knowledge that may be applied to virtually any situation that might arise in the life of the institution. Ironically, however, academic and professional expertise is not always effectively leveraged to address organizational issues. That was not the case in this instance, and leadership for all phases of the university response was informed by the knowledge base of thought leaders throughout the institution. The recognition and use of in-house knowledge reinforced confidence in leadership and contributed to a sense of pride within the community.

\subsection{Communication and Information}

Widely, consistently, and frequently communicating core values, relevant medical and health information, and campus updates related to policy decisions and plans represented another key element of the university's approach and cannot be stressed enough. Multiple communication channels were utilized at the institutional level including email, a regularly updated university website, virtual townhalls, webinars, and postings. The communication division of the university worked with senior leaders to craft clear messages consciously targeted to the information needs and concerns of students and their parents, faculty, staff, and other members of the community. These channels and messages were reinforced through audience-specific messages from campus chancellors/provosts, school deans, and other offices. Bolstered by frequent value-consistent messages, continuing updates, and a commitment to transparency, and various opportunities for two-way engagementFAQ sections, live webinars, query options on websites, and through other means-trust in the guidance provided by institutional leaders was established and continually reinforced. Systematic processes were also used to monitor, capture, and share pertinent information from external sources-science and health agencies, governmental agencies, peer institutions, faculty and staff, and community stakeholders. The communication and information activities described in this case focused on immediate needs. Over the longer term, reviews and reflections such as this one have considerable potential to contribute to discussions of the value information and knowledge can have within higher education institutions in crisis situations and more generally (Galagan; 1997; Gigliotti, 2020; Ruben, in press).

\subsection{Leadership and Management}

A third area where valuable lessons emerged relates to commonly referenced distinctions between leadership and management. Traditionally, leadership is seen as consisting of establishing a vision and enacting behaviors that mobilize colleagues to join in embracing a shared set of priorities, goals, and plans. Management generally is the term used to refer to actions associated with maintaining order and consistency through the enactment of systematic procedures and routines necessary to complete particular tasks (Kotter, 2012; Zaleznik, 2004). Management is often described as "keeping the trains running on time," while leadership is often characterized as "deciding where the trains should go."

This distinction, while a familiar one, has been criticized for failing to capture the fluid, interdependent, and permeable nature of these two functions as they operate in the ideal circumstance (Ruben, De Lisi and Gigliotti., 2021). We believe the case history described herein is an excellent example of the limitations of a leadermanager dichotomy. In fact, it can be argued that the fluidity and intersectionality of these two functions is a significant lesson that can be derived from the case. Each member of the leadership team and many of their colleagues have functioned as both leaders and managers in ways that have blended these two roles (Ruben, De Lisi and Gigliotti, 2021). Indeed, one take-away from the description of this complex crisis situation, and perhaps others, is that leadership-management is better characterized as defining end points on a continuum rather than a dichotomy. In this view, individuals on a leadership team-and managers - can be seen as working together to define and execute actions along the continuum as dictated by circumstance and need and guided by a shared and jointly created understanding of values, purposes, and priorities. 


\subsection{Broad-Based Collaboration and Problem Solving}

Quite clearly, the encouraging progress and outcomes to date in this case have benefitted immeasurably from the expertise of academic, professional, and administrative collaboration and guidance. By engaging individuals who are recognized administrative, academic, health/medical, and crisis-management leaders, the perspectives, expertise, and credibility of each domain were blended in a manner that enhanced the resulting plans, and their acceptance and adoption by members of the community who see their points of view reflected in the leadership guidance being provided.

\subsection{Leveraging Complexity and Multi-disciplinarity}

A somewhat related and quite vital insight to emerge from the case relates to the challenges presented by organizational complexity and multi-disciplinarity within a large university. While these features can certainly be a challenge in day-to-day decision making and operations, a case such as this demonstrates the substantial benefit that is present within a university community and its many divisions, disciplines, and departments. When these multiple talents are focused on a particular problem by academic, administrative, and professional experts, the power of this community of experts and the knowledge available with the institution becomes apparent.

\subsection{Leadership Integration of Institutional Knowledge and Expertise}

A last key insight to be mentioned follows from the previous one. It should also be noted that the most visible aspects of this case history represent only the tip of the iceberg, as is so often the case in such situations when they go well. The vaccination decision was but one piece of an ongoing, carefully planned and executed process beginning in January 2020 with early efforts to inform and protect the campus community and continuing today and into the future in efforts to anticipate and address challenges of the pandemic as they emerge.

Nonetheless, even this case history-incomplete in many respects-demonstrates not only the easily overlooked power, but also the potentially useful source of pertinent knowledge and subject matter expertise available within the university community. But to be useful, that expertise must be harnessed, leveraged, and coordinated. Academic conferences and writings on the value of interdisciplinarity, inter-professionality, and diversity were translated into action and influence-within the university, nationally, and across sectors in this instance. This case, then, becomes a reminder of what is possible within colleges and universities when knowledge resources, expertise, and technological support are harnessed not only with regard to a pandemic, but potentially across a wide range of subjects and topics of broad societal import. The case demonstrates the exceptional value knowledge resources of the academy can have if they are appropriately utilized. Perhaps the most significant take-away and a topic worthy of further thought and discussion is how higher education can more effectively and consistently leverage the extensive knowledge and information base that exists within each of our institutions in order to expand our leadership in a far broader range of community and societal challenges.

\section{Conclusion}

In the typical circumstance, a case history such as this is written when the events described have concluded. This case does not lend itself to this kind of conclusion because the COVID-19 pandemic is ongoing and evolving, as is the leadership efforts at Rutgers to maintain the health and safety of the community. Nonetheless, even given these circumstances, the narrative describing the Rutgers' efforts to exercise local and national leadership in combatting the COVID-19 pandemic provides an interesting example of how knowledge and expertise resident within the academic and professional staff community within a university can be identified, coordinated, and leveraged with impressive consequences. This case also provides a model of what might well be possible within colleges and universities in addressing various other institutional and public challenges confronting society with thoughtful attention to identifying and marshalling internal knowledge and expertise.

\section{References}

Associated Press, 2020. Johnson \& Wales to close Florida, Colorado campuses. Associated Press News June 25, 2020. Bellows, K. H., 2021. Quinnipiac poll finds divided opinions on Covid vaccine mandates at universities. The Chronicle of Higher Education, Aug 5, 2021.

Bhusry, M., Ranjan, J., and Nagar, R., 2012. Implementing knowledge management in higher educational institutions in India: A conceptual framework. Liceo Journal of Higher Education Research 29(1), pp. 34-46. DOI: 10.5120/3527-4805

Birnbaum, R., 1988. How colleges work: The cybernetics of academic organization and leadership. San Francisco, CA: Jossey-Bass. 
Bueller, J. (2015). A practical guide to academic transformation. Jossey-Bass.

Burt, C., June 28, 2021. State-by-state look at colleges requiring COVID-19 vaccines. University Business, June 28, 2021. Available at: https://universitybusiness.com/state-by-state-look-at-colleges-requiring-vaccines/“'Accessed 22 November 2021]

Chronicle Staff, 2020a. The Coronavirus is upending Higher Ed. Here are the latest developments, The Chronicle of Higher Education. March 3. Available at: https://www.chronicle.com/article/The-Coronavirus-Is-Upending/248175. [Accessed 23 November 2021]

Chronicle Staff, 2020b. As Covid-19 pummels budgets, colleges are resorting to layoffs and furloughs. The Chronicle of Higher Education. May 13. Available at: https://www.chronicle.com/article/As-Covid-19-Pummels-Budgets/248779. [Accessed 23 November 2021]

Cranfield, D. J. and Taylor, J., 2008. Knowledge management and higher education: A UK case study. Electronic Journal of Knowledge Management 1, (2), pp. 85-100. Available at: https://cronfa.swan.ac.uk/Record/cronfa15052. [Accessed 23 November 2021]

Davenport, T., Delong, D. and Beers, M.,1998. Successful knowledge management projects. Sloan Management Review, (39), pp. 43-57.

Durkee, A., March 25, 2021. Rutgers becomes first major university to require Covid-19 vaccination. Online Forbes. Available at: https://www.forbes.com/sites/alisondurkee/2021/03/25/rutgers-becomes-first-major-university-torequire-covid-19-vaccination/?sh=1ff1eb1848fe. [Accessed 23 November 2021]

Edelstein, M., June 10, 2020. Rutgers to support statewide contact tracing program. Rutgers Today. Available at: https://www.rutgers.edu/news/rutgers-support-statewide-contact-tracing-program. [Accessed 23 November 2021]

Fernandes, D., 2020. Amid coronavirus pandemic, a growing list of colleges in financial peril. Boston Globe Video. Updated May 8. Available at: https://www.bostonglobe.com/2020/05/08/metro/amid-pandemic-growing-list-collegesfinancial-peril/. [Accessed 23 November 2021]

Flaherty, C., 2020. Mounting faculty concerns about the fall semester. The Chronicle of Higher Education. June 30, 2020. Available at: https://www.insidehighered.com/news/2020/06/30/faculty-concerns-about-fall-are-mounting. [Accessed 23 November 2021]

Furstenberg, F., 2020. University leaders are failing. The Chronicle of Higher Education, June 26, 66(32), pp. 30-31. Galagan, P., 1997. Smart companies (knowledge management). Training and Development, 51(12), pp. 20-25.

Gigliotti, R. A., 2020. Crisis leadership in higher education: Theory and practice. New Brunswick, NJ: Rutgers University Press.

Goddard, A., 1998. Facing up to market forces, Times Higher Education Supplement, 13 November, pp. 6-7.

Golodryga, B. (Apr. 23, 2021). Rutgers official: Vaccine is the game changer for us. The Lead. CNN. Available at: https://www.cnn.com/videos/us/2021/04/23/colleges-requiring-covid-vaccines-golodryga-pkg-lead-vpx.cnn [Accessed 15 November 2021]

Hendrickson, R. M, Lane, J. E., Harris, J. T., and Dorman, R. H., 2013, Academic leadership and governance of higher education: A guide for trustees, leaders, and aspiring leaders of two- and four-year institutions. Sterling, VA: Stylus.

Holloway, J. S., Sept 3, 2021. Personal Communication.

Hosseini, Z., Sept 1, 2020. New Jersey medical school and university hospital to conduct trial over the next 25 months. Rutgers Today. Available at: https://www.rutgers.edu/news/rutgers-selected-site-covid-19-vaccine-clinical-trial. [Accessed 23 November 2021]

Kotter, J. P., 2012. Leading change. Cambridge, MA: Harvard Business Review Press.

Lawrence, S., 2020. S. E. Personal communication. May 2, 2020.

Murphy, J., 2020. PennLive. More than 1,000 faculty and other employees raise concerns about Penn State's fall reopening plans, PennLive Patriot-News. June 16, 2020. Available at: https://www.pennlive.com/news/2020/06/more-than1000 -faculty-and-other-employees-raise-concerns-about-penn-states-fall-reopening-plans.html. [Accessed 23 November 2021]

Nadworny, E., 2020. Can colleges survive Coronavirus? 'The math is not pretty," NPR, April 20. Available at: https://www.npr.org/2020/04/20/833254570/college-brace-for-financial-trouble-and-a-big-question-will-theyreopen-in-fall. [Accessed 23 November 2021]

New York Times, Jan 21, 2020. First patient with Wuhan coronavirus is identified in the U.S. (2020, May 7). The New York Times - Breaking News, US News, World News and Videos. Available at: https://www.nytimes.com/2020/01/21/health/cdc-coronavirus.html. [Accessed 23 November 2021]

Nuninger, W. and Chatelet, J-M., 2016. Handbook of research on quality assurance and value management in Higher Education-Information Science Reference. Hershey, PA: IGI Global. doi: 10.4018/978-1-5225-0024-7.

Paquette, G., 2020. Bashing administrators while the college burns: Denunciation, recrimination, and grandstanding are pit stops on the road to oblivion. The Chronicle of Higher Education, June 26, 66(32), pp. 32-33.

Redden, E., Sept. 21, 2021. Climbing toward vaccine compliance. Inside Higher Ed. Available at: https://www.insidehighered.com/news/2021/09/21/colleges-mandating-vaccines-see-progress-toward-compliance. [Accessed 23 November 2021]

Rowley, J., 2000. Is higher education ready for knowledge management? The International Journal of Educational Management, 14(7), pp. 325-333. https://doi.org/10.1108/09513540010378978

Ruben, B. D. (in press). Sustainable change in higher education: Principles and practices of effective leadership. Sterling, VA: Stylus. 
Ruben, B. D. (in press). Implementing sustainable change in higher education: Principles and practices of collaborative leadership. Sterling, VA: Stylus.

Ruben, B. D., 2020a. Leading in turbulent times: In search of a navigational system for this critical moment in the history of U.S. higher education, Nuventive. Available at: https://go.nuventive.com/white pages-b ruben. [Accessed 23 November 2021]

Ruben, B. D., 2020b. Contemporary challenges confronting colleges and universities: The Baldrige and Excellence in Higher Education approach to institutional renewal, Chronicle of Leadership and Management, 1(1), pp. 13-35.

Ruben, B. D., De Lisi, R., and Gigliotti, R. A., 2021. A guide for leaders in higher education: Concepts, competencies, and tools. second edition. Sterling, VA: Stylus.

Ruben, B. D., Mahon, G., Gigliotti R. A., Goldthwaite, C. 2021. Leadership and revitalization in a period of disruption and change: Adaptation and innovation in the Rutgers School of Health Professions. Excellence in Leadership and Management, 1. Oxfordshire, UK: Academic Conferences and Publishers International, pp. 19-31.

Rutgers Office of the President, Mar 25, 2021. Our path forward-COVID-19 vaccination and the fall term. Available at: https://www.rutgers.edu/president/our-path-forward. [Accessed 23 November 2021]

Rutgers testing program dashboard, Sept 11, 2020. Universitywide COVID-19 information. Available at: https://coronavirus.rutgers.edu/health-and-safety/testing-program-dashboard/. [Accessed 23 November 2021]

Rutgers Today, March 25, 2021. Rutgers to require COVID-19 Vaccine for Students. [Accessed 23 November 2021] Available at: https://www.rutgers.edu/news/rutgers-require-covid-19-vaccine-students.

Thomason, A., and O'Leary, September, 2020. Here's a list of colleges that require students or employees to be vaccinated against Covid-19. Available at: https://www.chronicle.com/blogs/live-coronavirus-updates/heres-a-list-of-collegesthat-will-require-students-to-be-vaccinated-against-covid-19. [Accessed 23 November 2021]

Update to the guide to returning to Rutgers -8/27/21, Aug 27, 2021. Rutgers universitywide COVID-19 information. Available at: https://coronavirus.rutgers.edu/update-to-the-guide-to-returning-to-rutgers-8-27-21/. [Accessed 23 November 2021]

Vedder, R., 2020. Colleges on life support face three choices: death, merge or survive, May 18. Available at: https://www.forbes.com/sites/richardvedder/2020/05/18/colleges-on-life-support-face-3-choices--death-merger-orsurvival/\#24cc6cb3fb2c. [Accessed 23 November 2021]

Weick, K. E., 1976. Educational organizations as loosely coupled systems. Administrative Science Quarterly, 21, pp. 1-19.

Zahneis, M., 2020. Plexiglass? That'll be \$135, please." The Chronicle of Higher Education, June 26, 66(32), pp. 6.

Zaleznik, A., Jan 2004. Managers and leaders: Are they different? Harvard Business Review. Available at: https://hbr.org/2004/01/managers-and-leaders-are-they-different. [Accessed 23 November 2021]

Zwickel, S., June 22, 2020. U-M Flint cuts 41\% of lecturers, citing dire financial outlook. Detroit Free Press, Published 6:00 am, June 22. Available at: https://www.freep.com/story/news/local/michigan/2020/06/22/um-flint-layoffslecturers-leo-michigan/3232929001/. [Accessed 23 November 2021] 